See Article page 663.

\section{Commentary: Law of diminishing returns}

\author{
Fraser D. Rubens, MD, MSc, FACS, FRCSC
}

The surgical revascularization component of the STITCH (Surgical Treatment for Ischemic Heart Failure) trial was designed to test the hypothesis that coronary artery bypass grafting plus guideline-directed medical therapy would improve survival as compared with medical therapy alone in patients with ejection fraction $<35 \%$. The trial comprised 610 patients in the surgery arm and 602 in the medical arm. ${ }^{1}$ The primary outcome of this study was allcause survival, and at a median follow-up of 9.8 years, there was a survival benefit of surgery that was statistically significant (hazard ratio, 0.84; 95\% confidence interval, 0.730.97).

In the current article, Doenst and colleagues ${ }^{2}$ have presented a cohort analysis looking specifically at the role of different degrees of renal insufficiency in this trial. A mortality benefit was only seen in patients with moderate renal insufficiency. Those with none-to-mild insufficiency and those with moderately severe insufficiency did not benefit in terms of survival. There were too few patients with severe renal insufficiency to make the call.

So what does this mean? This finding has opened the door for this reviewer to ponder various hypotheses. Could it be that normal renal function provides more latitude for optimization of medications with greater efficacy? And how do we explain the suboptimal results when renal function is moderately severely impaired? Is this just the reflection of the law of diminishing returns? Does the increased risk of death from renal failure catch up to the improved survival from surgery such that there is no overall benefit?

The authors turned to a composite of death and hospitalization, which was the secondary outcome in the original trial. Death and first hospitalization for cardiac cause are

\footnotetext{
From the Department of Surgery, University of Ottawa Heart Institute, Ottawa, Ontario, Canada.

Disclosures: Author has nothing to disclose with regard to commercial support.

Received for publication Feb 15, 2020; accepted for publication Feb 16, 2020; available ahead of print Feb 21, 2020.

Address for reprints: Fraser D. Rubens, MD, MSc, FACS, FRCSC, Department of Surgery, University of Ottawa Heart Institute, 40 Ruskin St, Ottawa, Ontario

K1Y 4W7, Canada (E-mail: frubens@ottawaheart.ca).

J Thorac Cardiovasc Surg 2022;163:673

$0022-5223 / \$ 36.00$

Copyright (c) 2020 by The American Association for Thoracic Surgery

https://doi.org/10.1016/j.jtcvs.2020.02.067
}

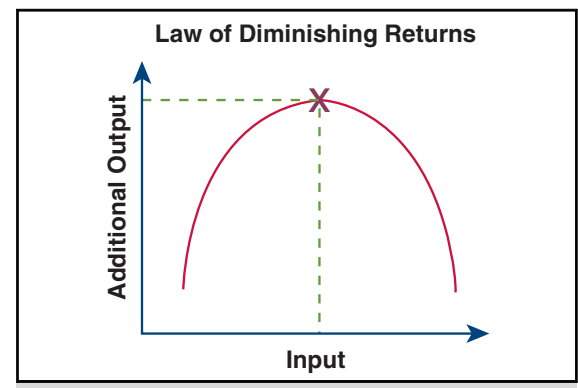

Finding the optimum degree of renal function in patients with ischemic cardiomyopathy who may benefit from surgery.

\section{CENTRAL MESSAGE \\ There is value in deeply exam- ining the relevance of outcomes of landmark clinical trials so we can offer a balanced approach to our patients and optimize their quality of life.}

vastly different consequences with disparate clinical relevance. Is it viable to combine them in this way? Its relevance is also limited, as hospitalization for heart failure is not infrequently a repeating event. Consider the following: what would be the more important clinical outcome after a surgical intervention? Patient A is admitted once after 1 month for heart failure but after optimization of treatment never comes back and dies peacefully at 5 years. Patient B is admitted 2 months after surgery but is repeatedly admitted every 2 months until death at 5 years. Based on my conceptions of the quality of life I strive for my patients, I think I would prefer to see the clinically relevant outcome of cumulative admission for congestive heart failure with all-cause death as a competing event.

We are obliging patients to live longer with heart failure, and the stark reality of its impact on quality of life is demanding us to clarify our goals to understand the patient experience in heart failure. Illuminating the relevance of trial outcomes will be essential to shape the way we translate research results in a patient-centric manner.

\section{References}

1. Velazquez EJ, Lee KL, Jones RH, Al-Khalidi HR, Hill JA, Panza JA, et al. Coronary-artery bypass surgery in patients with ischemic cardiomyopathy. $N$ Engl J Med. 2016;374:1511-20.

2. Doenst T, Haddad H, Stebbins A, Hill JA, Velazquez EJ, Lee KL, et al. Renal function and coronary bypass surgery in patients with ischemic heart failure. J Thorac Cardiovasc Surg. 2022;163:664-72.e3. 